Please do not remove this page

RMIT

UNIVERSITY

\title{
Vectors of knowledge exchange: the value of industry engagement to HASS PhDs
}

Barnacle, Robyn; Cuthbert, Denise; Schmidt, Christine; Batty, Craig

https://researchrepository.rmit.edu.au/esploro/outputs/9921901809501341/filesAndLinks?institution=61 RMIT_INST\&index=null

Barnacle, R., Cuthbert, D., Schmidt, C., \& Batty, C. (2020). Vectors of knowledge exchange: the value of industry engagement to HASS PhDs. Higher Education, 80(5), 973-987.

https://doi.org/10.1007/s10734-020-00528-z

Document Version: Accepted Manuscript

Published Version: https://doi.org/10.1007/s10734-020-00528-z

Repository homepage: https://researchrepository.rmit.edu.au

(c) Springer Nature B.V. 2020

Downloaded On 2023/04/26 22:08:59 +1000

Please do not remove this page 


\title{
Vectors of knowledge exchange: the value of industry engagement to HASS PhDs
}

Corresponding author: Robyn Barnacle

School of Graduate Research, RMIT University, PO Box 2476, Melbourne, 3001 Australia

robyn.barnacle@rmit.edu.au

\author{
Robyn Barnacle ${ }^{1}$ Denise Cuthbert ${ }^{2}$ Christine Schmidt ${ }^{3}$ Craig Batty ${ }^{4}$ \\ ${ }^{1}$ School of Graduate Research, RMIT University, Melbourne. ORCID: 0000-0002-5277-0918 \\ ${ }^{2}$ School of Graduate Research, RMIT University, Melbourne. ORCID: 0000-0003-2959-4546 \\ ${ }^{3}$ School of Graduate Research, RMIT University, Melbourne. ORCID: 0000-0002-6806-6669 \\ ${ }^{4}$ School of Communication, University of Technology Sydney, Sydney. ORCID: 0000-0002-8542-4763
}

\begin{abstract}
This article investigates the value of Humanities, Arts and Social Sciences (HASS) candidates’ prior industry networks and experiences as they intersect with doctoral study, as assessed by a group of HASS PhD graduates. While the phenomenon of industry engagement in PhDs across HASS and STEM is widely recognised, the value of these relationships to the $\mathrm{PhD}$ experience is less understood. This is particularly the case in HASS PhDs given the opportunities afforded to this predominantly mature-aged cohort of pre-existing professional networks.

In our previous work on this topic, we showed that engaging with industry throughout the HASS PhD research lifecycle is widespread, and that networks may have their genesis prior to commencement and persist into careers post-graduation. In this article we subject these networks to finer-grained analysis. Based on 16 in-depth interviews, we investigate the value HASS PhD graduates ascribe to their industry networks pre, during and post-graduation.

Our analysis suggests industry engagement during the $\mathrm{PhD}$ contributes value in two key ways: by facilitating candidate learning, in the form of research design and data collection related activities, and for knowledge exchange. These insights are further enhanced by development of a novel analytical model that measures the extensiveness, or continuity, of industry engagement across the $\mathrm{PhD}$ lifecycle. Comparative analysis reveals a correlation between enduring industry engagement and academic careers post-graduation, suggesting additional value in the form of a highly industry integrated HASS academic labour force. Our findings suggest HASS PhDs can function as an important and hitherto under-recognised industry engagement vector, contributing added value to the research process with multiple potential beneficiaries.
\end{abstract}

Keywords: pre-doctoral professional networks; knowledge transfer and exchange; Humanities, Arts and Social Sciences (HASS); value of a PhD; industry engagement. 


\section{Introduction}

It is widely recognised that some $\mathrm{PhD}$ candidates bring pre-existing professional experience and networks into the degree, including within the humanities, arts and social sciences (HASS). How this informs and enhances educational experience and knowledge exchange is less understood. Indeed, $\mathrm{PhD}$ candidates are often treated as 'empty vessels' from a capability development perspective and are arguably unlikely to be considered at all from a research translation perspective. The research presented in this article challenges these assumptions. We investigate the value of professional networks in a subset of HASS PhDs. Adopting an inclusive definition of industry to encompass all sectors beyond higher education, we trace professional network formation and impact into, through and beyond graduation. The industry engagement practices that we capture are not curriculumbased, program-wide innovations, but rather occur on the scale of the individual candidate who draws on and mobilises pre-doctoral professional networks or expertise.

Such candidates represent an important and hitherto largely overlooked vector of industry engagement between the academy and other sectors. While perhaps counter intuitive, this is particularly so given the tendency of HASS PhD graduates to remain within the academy (Barnacle et al. 2019; OECD. Stat 2019; Duke Graduate School 2018; Robertson 2017; Jonker 2016). These 'hidden in plain view' activities often go un-recorded or unrecognised because they do not readily conform with university research engagement reporting requirements, which tend to assume that the engagement must be initiated or commenced within and by the university. For example, in Australia, this engagement and impact agenda has recently been formalised through a subset of the Excellence in Research for Australia scheme, which assesses metrics and case studies from academic researchers but excludes PhD candidates (Australian Research Council 2019).

Concern about the relevance of the PhD to industry is widespread across all disciplines and most advanced education systems (Cunningham et al. 2016; Golde and Walker 2006; Guerin 2019; Howard 2015; McAlpine and Amundsen 2016; McCarthy 2017; Universities Australia 2016; Hasgall et al, 2019). Numerous corresponding initiatives have arisen world-wide, such as the Danish Industrial PhD program (University of Copenhagen, 2019), the European Commission innovative training networks (n.d.) the Marie Skłodowska-Curie Actions Program (European Commission Horiozn, n.d.), the UK Engineering \& Sciences Research Council (EPSRC, 2014) and Australian Cooperative Research Centres. Typically, the lens applied to these issues focuses on refashioning PhD programs to meet the employment needs presented by diverse career trajectories (Cunningham et al. 2016; Guerin 2019; Higgins and Daniels 2015).

We have observed, however, that much of this debate is underpinned by a neophyte conception of the typical $\mathrm{PhD}$ candidate as something of an empty vessel, devoid of previous professional experience and in need of additional support to build employability, research translation and other career relevant skills (see Cuthbert and Molla 2015). This neophyte conception is highly questionable. Based on age profile alone, potentially many $\mathrm{PhD}$ candidates enter the degree with relatively high levels of pre-existing professional experience. OECD statistics (2015) reveal that only 37\% of global doctoral level enrolments were by those under 30 years of age, and a further 30\% are aged between 30 and 39 years (OECD.Stat 2019). According to Pearson et al. (2011: 528), the assumption that the normative $\mathrm{PhD}$ candidate is in their twenties has led to 'undervaluing current and prior work experience and ignores the reality of older and mid-career professionals undertaking doctorates'. Although there has been 'some refurbishment in Australia' of the neophyte stereotype, recognition of existing professional experience is not necessarily reflected in policy (Pearson et al. 2011). For example, in Australia we see an ever-increasing focus on providing PhD candidates with 'work ready' opportunities through industry placements (Cunningham et al. 2016; Howard 2015). There is a tendency, that is, for employability considerations to overlook the significant existing professional experiences, interests and networks of some candidates. Moreover, a focus on the $\mathrm{PhD}$ at the institutional level risks obscuring all but curricular and program level considerations when examining such matters and fails to recognise the industry-connectedness that enters the university with some candidates.

While this issue has relevance across the disciplines, including Science, Technology, Engineering, Mathematics and Medicine (STEMM), it is particularly apparent in HASS where a significant proportion of PhD candidates are mature aged and may be mid-career professionals (OECD. Stat 2019; Robertson 2017). Despite these demographics and high overall graduate employment, employability concerns remain the abiding concern in the literature. This includes an increasing focus on the preparation of HASS PhD graduates for non-academic careers (Guerin 2019; McAlpine and Austin 2018; Mewburn et al. 2018), despite academia being the most likely career path for this cohort (Barnacle et al. 2019; Duke Graduate School 2018; Jonker 2016; School of Graduate Studies University of Toronto 2018; Stanford Institutional Research \& Decision Support 2018; UBC Faculty of Graduate \& Postdoctoral Studies 2017). 
While employability should not be dismissed as an important issue for a proportion of $\mathrm{PhD}$ graduates, our contention is that it may obscure other motivations for embarking on $\mathrm{PhD}$ research. One such motivation is that of pursuing topics of interest that have emerged in the context of existing professional experience; motivation that has emerged from - rather than with a view to - employment. Additionally, insufficient attention has been directed to how the pre-existing professional experience of $\mathrm{PhD}$ candidates may contribute to researcher formation and development as well as knowledge exchange and graduate outcomes.

In our previous work on this topic (Barnacle et al. 2019), we showed that despite securing employment in higher education at higher rates post-graduation than their STEM-M counterparts, HASS PhD graduates often enjoy ongoing and diverse forms of relationships with the non-academic community. This supports findings from several other studies internationally (Duke Graduate School 2018; Jonker 2016; School of Graduate Studies University of Toronto 2018; Stanford Institutional Research \& Decision Support 2018; UBC Faculty of Graduate \& Postdoctoral Studies 2017). We showed that industry networks range across sectors and may have their genesis prior to commencement of the $\mathrm{PhD}$ and persist beyond candidature into post-graduation academic careers.

In this article, we report on the second phase of this project that subjects these networks to finer-grained analysis. Through in-depth interviews, we investigate the value HASS PhD graduates ascribe to industry networks pre, during and post-graduation. Our analysis suggests industry engagement contributes value in two key ways: by facilitating candidate learning, in the form of research design and data collection related activities, and knowledge exchange. Further comparative analysis reveals a potential correlation between the scope of industry engagement and academic careers post-graduation. Our analytic model of HASS industry engagement extensiveness suggests $\mathrm{PhD}$ research with multiple touchpoints across the research lifecycle, spanning pre, during and post-graduation phases, may confer additional value in the form of a highly industry engaged HASS academic labour force. Potential beneficiaries are industry, universities and candidates themselves. We emphasise that this study examines the $\mathrm{PhD}$ graduates' view of the value of industry engagement to their experience of the $\mathrm{PhD}$. Reflecting this focus, we refer throughout to industry engagement rather than end-user engagement as it is beyond the scope of the study to determine the extent to which industry partners benefitted from these partnerships. The utility of in-candidature industry engagement to the industry partners is recommended for further research.

These findings contribute to existing research that scopes a wide range of industry and end-user interactions undertaken by HASS academics in Europe and the UK (Ackers et al. 2014; Hughes et al. 2011; Hughes et al. 2016). Previous studies have focused on pre-doctoral motivations for study and postdoctoral academics (see Brailsford 2010; Gardner 2010; Holbrook et al. 2014; Litalien et al. 2015; Moxham et al. 2013; Skakni 2018), or prior professional experience (Cumming 2007; Klein and Rowe 2008; Pearson et al. 2011). Less attention, however, has been directed to how professional experience and networks developed prior to and during the $\mathrm{PhD}$ enhance research training and graduate outcomes (Ackers et al, 2014; Hughes et al, 2014; Olmos-Peñuela et al. 2014). We extend this field of knowledge further, therefore, by showing how the HASS PhD can function as an important vector for the value-add of industry engagement. Our insights are enabled by development of a novel analytical model that measures the scope of industry engagement throughout the $\mathrm{PhD}$ lifecycle.

\section{Researcher socialisation and the PhD}

The concept of socialisation has long been established in the research training context to address how individuals embarking on a $\mathrm{PhD}$ are inducted into a research community and its cultures and practices of knowledge production (Delamont and Atkinson 2001; Golde and Walker 2006). While numerous disciplinary and other programmatic differences exist globally, candidature typically takes the form of an immersive period of extended, independent enquiry supported by academic advisors. Non-university partners or networks introduces a third, external element to what has traditionally been perceived as a dyadic relationship between candidate and advisor, set primarily within the cloistered walls of academia (Cunningham et al. 2016; Howard 2015; Innovate UK 2018; Markuerkiaga et al. 2014; University of Cambridge Enterprise 2015). This traditional model, however, is considered neither accurate as a description of current practice, nor sufficient as a model within numerous advanced higher education systems. Australia is not alone in seeing a steady increase in $\mathrm{PhD}$ research with an applied orientation, and a decrease in basic or so-called 'pure' research (Norton et al. 2018). Such trends are world-wide and reflect transformations in the role and purpose of scholarly research, and the origin of research problems (Gibbons et al. 1994; Molla and Cuthbert 2018). Within this context, it can be tempting to assume that applied research is technology directed in contrast to pure research arising from disciplinary norms and paradigms. Where the former is rooted in industry, the latter stems from the discipline. 
In practice, however, this bifurcation is something of an oversimplification. Concepts such as 'user-inspired basic research' have emerged to capture the overlap and interplay that increasingly occurs between basic and applied research (see Stokes’ discussion of Pasteur’s quadrant, 1997).

The creative arts is one area in which this overlap is particularly apparent, highlighting the significant disciplinary differences that are also at play. For example, Hughes et al. (2011) found that Arts and Humanities academics are less likely to categorise their research as applied, whereas Creative Arts and Media academics were likely to classify their research as user-inspired and reflect diverse research foci. This is especially the case with respect to HASS PhDs, where knowledge transfer predominantly takes the form of people-based, problemsolving and community-based modes of engagement (Ackers et al. 2014; Hayden et al. 2018; Hughes et al. 2011; Hughes et al. 2016; Olmos-Peñuela et al. 2014). The tendency to focus on formal industry-based arrangements typified by engagements in science, technology and medical research, therefore, risks reducing non-university engagement to industry/commercial engagement, effectively obscuring other modes and sectors.

\section{Industry engagement and the $\mathrm{PhD}$}

Engagement with non-university organisations during the $\mathrm{PhD}$ is an important socialization mechanism for enhancing the candidate experience and employability by contributing to the formation of researcher capabilities as well as professional and research partnerships post-graduation. The introduction into $\mathrm{PhD}$ programs of cadetships, internships and other industry-linked projects fulfils obvious economic and community development incentives for governments eager to promote knowledge transfer and partnerships between universities and nonuniversity organisations. Indeed, it has become a policy orthodoxy in developed Higher Education systems such as the UK and Australia that the level of industry engagement of $\mathrm{PhD}$ candidates is insufficient and needs to increase (Bell et al. 2015; Cunningham et al. 2016; Howard 2015; Innovate UK 2018; Markuerkiaga et al. 2014; University of Cambridge Enterprise 2015). This is despite a variable and patchy evidence base.

Recent Australian research has offered important base-line data from which to examine assumptions with respect to industry engagement in the $\mathrm{PhD}$ (Bentley et al. 2017). This shows that while engagement with industry may typically be considered the domain of Professional Doctorates, it is increasingly the norm within PhDs. Bentley et al. established that contact with non-university organisations is widespread during PhDs across all HASS and STEM disciplines. The type and depth of such contact, however, varies considerably. Deep engagement with non-university organisations during the $\mathrm{PhD}$ is uncommon across all disciplines, but where it does occur it is likely to be in STEM-M disciplines. Deep engagement, for example, might include financial support, formal external supervision and industry placements. Such research might be described as applied in contrast to basic or pure research, due to its industry funding, direction and / or co-supervision being determined by an industry sponsor. While such research was found to be uncommon in HASS, Bentley et al. found widespread informal engagement with non-university organisations in these disciplines. This is consistent with the work of Hughes et al. (2011: 14) who found multiple, varied and sometimes complex forms of knowledge exchange and engagement between universities and non-university organisations in the Arts and Humanities, albeit with limited potential for commercialisation. Examples of informal industry engagement found by Bentley et al. include topic advice and primary or secondary data collection from an industry partner.

One of the key differences between formal and informal industry engagement is the extent of institutional involvement: whereas universities are likely to be involved in transactions involving the former, they are unlikely to be involved in the latter. It follows that knowledge of industry engagement also differs along broaddisciplinary lines. Whereas institutional involvement assures knowledge of deep industry engagement in STEM$\mathrm{M}$, a lack of institutional involvement contributes to limited knowledge of informal industry engagement - in STEM and HASS. Informal, non-university-initiated arrangements suggest a non-binary, complex genealogy through which research problems and projects may be formed and accomplished. In such cases, the candidate might be understood as positioned between industry and the discipline, neither 'steward of the discipline' nor industry intern: instead, negotiating the two (Cunningham et al. 2016; Golde and Walker 2006).

Looking specifically at HASS disciplines, it is this complex relationship we seek to better understand. Given that HASS PhD candidates are more likely than STEM to be mid-career professionals (OECD. Stat 2019; Robertson 2017), we are interested in how the former cohort utilise pre-existing professional networks or experience informally within the $\mathrm{PhD}$. What added value do pre-existing professional networks or experiences confer to the HASS PhD? And how might these be useful for careers post-graduation?

\section{Study approach and method}


Our approach draws on the field of valuation studies, which examines the social practices of valuation - or how value and values are established, transmitted and contested within a field of practice (see Kjellberg et al. 2013; Lamont 2012). In this case, we examine the value of professional experience and networks to the research process and outcomes in HASS PhDs. By adopting this approach, participants are encouraged to reflect holistically on the role of industry relationships in their research and professional activities. Valuation studies promotes a reflexive approach that prompts 'interlocutors to reflect on how the biographical, institutional and epistemic dimensions of the decisions they take related to their past, current and future careers are entangled' (Fochler et al. 2016). Moreover, understanding the flow of knowledge exchange requires examining participants' social and cultural contributions 'to explore aspects of value that cannot be readily translated into price’ (Kjellberg et al. 2013: 19).

The research reported here comprised 16 in-depth interviews with a sample of HASS PhD graduates (for part one of the study, see Barnacle et al. 2019). The interviews were conducted via Skype or in person and were loosely structured to allow participants to extrapolate where necessary. The interviews were between 40 and 95 minutes long, anonymized and transcribed verbatim for analysis. Investigator triangulation was employed for the data analysis with three researchers independently reviewing and discussing the transcripts to establish consistency. Transcripts were coded into themes relating to key questions and variables, such as: previous professional activities; nature and extent of in- and post-candidature non-university engagement; PhD graduate outcomes. Analysis was guided by a typological approach to systematically categorise data by types of industry engagement, and continuity and expansion of networks, with the aim of understanding the trajectory of graduates' research projects and interface with non-university sectors. Ethics approval for parts one and two of the project was granted by the relevant university Human Research Ethics Committee, and all data collection was completed in October 2018.

Table 1 provides a summary of participant demographics. Ten identified as female and six as male. Twelve participants completed their degree as local students and four were international. Most participants (9) completed their degree recently (since 2015) and seven prior to 2015. Of the HASS disciplines included in the sample, education and communication / graphic design accounted for half of all participants, at five and three respectively. The majority (10) were mid-career professionals prior to embarking on PhD study, with the remainder being either early to mid-career (5) or late career (1).

Table 1: Participant demographic overview

\begin{tabular}{|c|c|c|c|c|c|}
\hline HASS Field of Research & $\begin{array}{l}\text { Professional Career } \\
\text { Stage prior to } \mathrm{PhD}\end{array}$ & \# & Gender & $\begin{array}{c}\text { PhD } \\
\text { Graduation } \\
\text { Year } \\
\end{array}$ & $\begin{array}{l}\text { Enrolment } \\
\text { Status }\end{array}$ \\
\hline Architecture $=1$ & Mid & 1 & Female & 2017 & Domestic \\
\hline \multirow{3}{*}{$\begin{array}{l}\text { Communication \& } \\
\text { Graphic Design = } 3\end{array}$} & \multirow[b]{2}{*}{ Mid } & \multirow[b]{2}{*}{2} & \multirow[b]{2}{*}{ Female } & 2016 & Domestic \\
\hline & & & & 2011 & International \\
\hline & Early & 1 & Male & 2008 & Domestic \\
\hline Creative Writing = 1 & Late & 1 & Female & 2017 & Domestic \\
\hline \multirow{5}{*}{ Education $=5$} & \multirow{3}{*}{ Mid } & \multirow{3}{*}{3} & \multirow{3}{*}{ Female } & \multirow{2}{*}{2015} & International \\
\hline & & & & & Domestic \\
\hline & & & & 2012 & Domestic \\
\hline & Late & 1 & Malo & 2017 & Domestic \\
\hline & Mid & 1 & vale & 2013 & International \\
\hline \multirow{2}{*}{$\begin{array}{l}\text { Environment \& } \\
\text { Community } \\
\text { Sustainability = } 2\end{array}$} & Early to Mid & 1 & \multirow{2}{*}{ Male } & \multirow{2}{*}{2013} & Domestic \\
\hline & Mid & 1 & & & International \\
\hline \multirow{2}{*}{$\begin{array}{l}\text { Studies in Human } \\
\text { Society = } 2\end{array}$} & \multirow{2}{*}{ Early to Mid } & \multirow{2}{*}{2} & \multirow{2}{*}{ Female } & 2015 & \multirow{2}{*}{ Domestic } \\
\hline & & & & 2018 & \\
\hline \multirow{2}{*}{ Visual Arts = 2} & \multirow{2}{*}{ Mid } & \multirow{2}{*}{2} & Female & 2016 & Domestic \\
\hline & & & Male & 2000 & Domestic \\
\hline
\end{tabular}




\section{Findings \\ Industry contribution to the HASS PhD}

Significantly, all participants reported some degree of engagement with non-university sectors during candidature. To understand better the role of this engagement in the research process, we sought participants' views on why and how these industry partnerships formed and the contribution to their research. Specifically, we sought to understand the value of these relationships in terms of candidates' socialisation into research communities and practices. Our analysis of the findings suggests industry engagement activities contribute value to HASS PhDs in two key ways:

- Candidate learning: contribution to research design considerations and data collection activities.

- Knowledge exchange: knowledge and information sharing opportunities between candidates and industry partners

Firstly, with regards to candidate learning, we found that all bar four participants reported consulting industry in research design considerations and all bar two reported data-collection involving industry. These partnerships comprised, in descending order of significance: the public sector, community sector, private sector or other industry involvement. Consultation provided access to research participants in numerous ways, such as recruitment through community organisations (P11, P13), or access to existing datasets. Crucially, partnerships were initiated through pre-existing networks rather than formal university mechanisms. For example, one participant states: “I didn't need to spend the first part of my PhD establishing a network. Due to [existing] links with industry ... these organisations made it happen. They felt my project was worthwhile and really trusted me” (P13). Industry relationships, therefore, were facilitated by previous professional experience, whether directly or indirectly.

Secondly, given industry engagement contributed extensively to learning during candidature, it is perhaps unsurprising that we also found widespread knowledge exchange activities. All bar two participants reported knowledge exchange activities, such as consultancy services, lectures, reports and exhibitions. These activities exclude traditional scholarly outputs and are not intended to be comprehensive of all outputs arising from the research. Examples of knowledge exchange between participants and industry partners include:

- $\quad$ lectures and talks to environmental advocacy organisations (P1, P3) and community health-related groups (P11, P13);

- $\quad$ partnering with a World Heritage site community group to market products online (P7);

- curriculum development activities (in the compulsory school sector) (P5, P9, P14),

- $\quad$ writing reports for government and providing advice to ministers (P13);

- $\quad$ co-authoring reports with community environmental and health-related organisations (P1, P3);

- $\quad$ partnering with industry software developers to develop new products (P6);

To illustrate the value of industry relationships over the research lifecycle, below we provide two concrete examples of what happens in HASS PhD industry engagement. These examples exemplify the extensive industry engagement cases discussed further below.

\section{Example 1 - P1}

Pre-candidature: The participant had previous professional experience as an architect and energy consultant, including working with government departments and councils on retrofit trials.

PhD project: An investigation of the relationship between residential energy efficiency and health.

Research design / data collection: Pre-existing networks with a government research organisation and local councils allowed the participant to 'piggy-back off these connections for their studies'. These non-university partners provided secondary data and access to households for a case study.

Project outcomes: New knowledge was created on householder practices and strategies for increasing energy efficiency, such as the design of energy retrofit interventions for the health and well-being of lowincome households. Key outcome for the participant: "I've got this network I can draw on with my new ideas."

Postdoctoral career: University lecturer. The participant enjoys strong connections with state and Federal government, municipal councils and not for profit environmental organisations. 
Summary: Pre-existing professional experience and networks provided the impetus to embark on a PhD and shaped the eventual PhD project. Working in post-secondary education on completion has led to ongoing industry projects driven from inside the academy. University employment has meant "bringing my expertise to the school".

\section{Example 2 - P13}

Pre-candidature: The participant worked in addiction rehabilitation centres as a counsellor and in research and policy development. The $\mathrm{PhD}$ was designed to address a lack of research with this client group.

PhD project: Youth sociology and social policy associated with young people's pathways in and out of problematic drug-use.

Research design / data collection: Collaboration with previous employer to investigate life histories of young people with substance abuse problems. The organisation trusted the participant due to an existing professional relationship and was keen to support a research project that they would otherwise be unable to fund.

Project outcomes: Development of a toolbox for practitioners in youth alcohol and other drugs field that provides current information and literature to support their work. In addition to academic publications, corporate reports and media coverage, the project led to consultancy work as an advisor to a government minister on policy issues related to disadvantaged youth, such as gender and substance abuse issues.

Postdoctoral career: Early career research fellowship followed by a tenured position as a university lecturer. The participant reports that their networks expanded due to the authority and independence conferred by university employment: "I wouldn't have been able to advise a minister if I was aligned with one particular organisation."

Summary: Participant regularly invited to contribute to government networks and continues to undertake projects with not-for-profit organisations focused on solving drug and other problems affecting young people. A transition to the academy on completion of the $\mathrm{PhD}$ has not impeded ongoing research projects with industry partners. The participant claims: "my industry experience opens a lot of doors in terms of research projects”.

These examples provide insight into the role of professional, community and government networks and connections HASS candidates bring into $\mathrm{PhD}$ projects, including access afforded to resources that would otherwise be unavailable. In the case of P1, for example, pre-existing professional experience and networks provide the impetus to embark on a $\mathrm{PhD}$ and the shape of the $\mathrm{PhD}$ project itself. In the case of $\mathrm{P} 13$, collaboration with a previous employer provided access to a client group that would have been inaccessible otherwise. In both cases, previous professional experience provided the necessary trust for collaborations to succeed.

These partnerships also create pathways to impact. Both examples illustrate the benefits of partnering with nonuniversity organisations during the $\mathrm{PhD}$. The professional networks attained pre-PhD and subsequently developed during the $\mathrm{PhD}$ can result in ongoing industry projects driven from inside the academy. In the words of P1: "it gives me so much clout and confidence ... it gives me a much better standing ... and it is translating the findings from my PhD into real life” (P1). Such examples illustrate the significant potential of HASS PhDs as enablers of knowledge transfer between researchers and diverse stakeholders.

Before turning to further comparative analysis, we note an important caveat: the overwhelming rate of incandidature, industry engagement in our sample may be a product of self-selection. That is, while we invited all survey respondents from part one of the study to participate in the interviews, it may be that those more likely to accept had engaged with industry during candidature. If this is the case, it is a skewed yet fortuitous result as it provides a rich dataset with which to examine this phenomenon. Given existing research has established widespread HASS industry engagement, as discussed above, we are confident this result represents an important, not atypical, subset of HASS graduates. To be clear, however, it is beyond the scope of this study to determine the generalisability of these findings: this should be taken up in further research. 


\section{Industry engagement trajectories and extensiveness}

Given the prevalence of industry engagement in this cohort, the question of differentiation arises: are industry networks activated more extensively in some cases than others and is there variation in the value that is created, or the benefits, in terms of candidate learning and knowledge exchange? To address these questions, we sought to measure the extensiveness of industry engagement across the PhD lifecycle and correlate this with postgraduation outcomes. The result is an evaluative model of industry engagement extensiveness - see Table 2.

Table 2 provides comparative, aggregated data on the industry engagement activities of our cohort in which to evaluate its extent, or continuity, across the $\mathrm{PhD}$ lifecycle. Previous and current occupation is also included to show the overall career trajectories of participants. To ascertain the relative scale of industry touchpoints, the model includes a count of all reported engagement activities. These have been grouped thematically in terms of the contribution to candidate learning, comprising research design and data collection, and knowledge exchange, or information sharing, between candidates and industry partners. While this measure flattens qualitative differences in scale of engagement, it nonetheless provides a useful snapshot of continuity, or the extent to which engagement activities endured across the research lifecycle. The total number of reported cases are recorded in each cell and colour coded accordingly. Results are presented in descending order of magnitude to reveal relative industry engagement extensiveness.

Table 2: Comparative analysis: industry engagement extensiveness

\begin{tabular}{|c|c|c|c|c|c|}
\hline \multirow[b]{2}{*}{ \# } & \multirow{2}{*}{$\begin{array}{l}\text { Employment } \\
\text { sector, pre- } \\
\text { candidature }\end{array}$} & \multicolumn{2}{|c|}{ Candidate Learning } & \multirow{2}{*}{$\begin{array}{l}\text { Knowledge } \\
\text { Exchange }\end{array}$} & \multirow{2}{*}{$\begin{array}{c}\text { Employment } \\
\text { sector, post- } \\
\text { graduation }\end{array}$} \\
\hline & & $\begin{array}{c}\text { Research } \\
\text { Design }\end{array}$ & Data Collection & & \\
\hline & \multicolumn{5}{|c|}{ High level industry engagement } \\
\hline P1 & Private Sector & 3 & 1 & 4 & University \\
\hline P7 & Public Sector & 2 & 2 & 4 & University \\
\hline P3 & Public Sector & 2 & 1 & 4 & University \\
\hline $\mathrm{P} 11$ & Public Sector & 2 & 2 & 3 & University \\
\hline \multirow[t]{2}{*}{$\mathrm{P} 13$} & NGO & 2 & 2 & 3 & University \\
\hline & \multicolumn{5}{|c|}{ Medium level industry engagement } \\
\hline P6 & Own Enterprise & 2 & 1 & 3 & Private Sector \\
\hline $\mathrm{P} 4$ & Own Enterprise & 1 & 1 & 3 & University \\
\hline $\mathrm{P} 10$ & Public Sector & 1 & 1 & 2 & Public Sector \\
\hline $\mathrm{P} 2$ & Public Sector & 1 & 1 & 1 & Public Sector \\
\hline P9 & Public Sector & 1 & 1 & 1 & Public Sector \\
\hline \multirow[t]{2}{*}{$\mathrm{P} 16$} & Public Sector & $\mathbf{0}$ & $\mathbf{0}$ & 3 & University \\
\hline & \multicolumn{5}{|c|}{ Low level industry engagement } \\
\hline $\mathrm{P} 5$ & Public Sector & $\mathbf{0}$ & 1 & 1 & Private Sector \\
\hline P8 & Public Sector & 1 & 1 & $\mathbf{0}$ & Public Sector \\
\hline $\mathrm{P} 12$ & Public Sector & 1 & 1 & $\mathbf{0}$ & Public Sector \\
\hline $\mathrm{P} 14$ & Public Sector & $\mathbf{0}$ & 1 & 1 & University \\
\hline $\mathrm{P} 15$ & Private Sector & $\mathbf{0}$ & 0 & 2 & University \\
\hline
\end{tabular}

Touchpoint Scale: $\mathrm{n}=$ count of reported engagement activities

\begin{tabular}{|l|l|l|l|l|}
\hline 0 & 1 & 2 & 3 & 4 \\
\hline & & & & \\
\hline
\end{tabular}

Our comparative model reveals three broad bands of industry engagement extensiveness: high, medium and low. Participants are evenly distributed across these bands. Cases on the high end of the scale enjoy multiple, enduring industry touchpoints spanning the all phases of candidature, from research initiation, data-collection, through to various research exchange related activities. In these cases, all aspects of the research process include industry, often in multiple ways, particularly the research design and knowledge transfer phases. This contrasts with the medium and low band cases of industry engagement extensiveness where industry touchpoints may be limited to one or two instances. While all cases of industry engagement confer value, in terms of either candidate learning or knowledge exchange, this analysis suggests there are degrees of value-add.

Indeed, a notable trend is revealed: all participants in the high industry engagement band are employed in universities post-graduation. Interestingly, while post-graduation employment sector is a consistent feature of 
this cohort there is no pattern regarding previous occupation. In other words, this cohort comes to the $\mathrm{PhD}$ from diverse backgrounds in the public and private sectors, and NGO's. The only common feature linked to employment sector post-graduation appears to be the continuity of industry engagement enjoyed during candidature as measured by the multiple enduring engagement touchpoints during the research lifecycle.

\section{Discussion}

Our analysis of the findings of this study suggests three key dimensions of value arising from industry engagement in HASS PhDs.

The first dimension of value is the contribution to learning. Whether through pre-existing networks or a professional skill set, industry engaged HASS PhDs mobilise industry partnerships to enhance and inform research design and data collection related activities. These benefits to the research process arise from professionally cultivated networks, skills and capabilities. Our findings suggest non-university organisations had confidence in these collaborations, either because there was an established and trusted relationship due to the participant's previous work in the sector, or because the candidate presented with sufficient professional experience to satisfy the non-university partner. In both cases, existing professional experience was a key enabling factor in the capacity to unlock this value-add to the research lifecycle. These findings contrast with existing research which suggests institutionalization of the collaborative arrangement is a key precondition (Thune, 2009).

The second dimension of value arising from industry engagement in HASS PhDs is knowledge exchange. We found widespread translation of research into so-called real-world impacts, or those beyond the outputs of scholarly dissemination. This includes profiling and sharing research outcomes via social media platforms and contributing as co-authors to non-academic publications designed to reach government, professional and general audiences. As one participant states with respect to their collaboration with a private sector software developer: "I really felt like I was seeing an actual impact on communities..." (P6). While our study does not, however, measure actual impact, the findings demonstrate the potential of HASS PhDs in this regard. Raddon and Sung (2009: 80) argue it is imperative to investigate these under-researched areas to build an understanding of the type of contributions and roles $\mathrm{PhD}$ graduates 'play in knowledge creation, creativity and innovation'. Our findings address this call by confirming the adaptive and resourcefulness of HASS PhDs in engaging with industry to address real-world problems. These findings also confirm other studies showing HASS research translation has the potential to deliver benefits in the form of social inclusion, health, education and social enterprise innovation, to name just a few areas that have been well documented in European and UK reports (Ackers et al. 2014; Hughes et al. 2011; Hughes et al. 2014; Hughes et al. 2016).

These findings challenge current discourses on the translation of $\mathrm{PhD}$ research and university research more generally which tends to be skewed in favour of the creation of value through the commercialisation of research to the exclusion of non-commercial modes of research translation (Australian Research Council, 2019). As others have observed about HASS PhD graduates, in the typical neoliberal university, 'scientific and policy debates are usually dominated by a focus on technology transfer and commercialization activities and [HASS] research is relatively marginalised in policy formation' (Olmos-Peñuela et al. 2014: 697). The findings of our research reinforce this observation and suggest a need to pay more attention to industry engagement in HASS.

The third dimension of value arising from industry engagement in HASS PhDs is to employers, particularly universities. Our findings show variation in the scale of benefit attributable to industry engagement. While industry engagement appears to be widespread, a high band cohort of HASS PhDs appear to be particularly adept at leveraging industry engagement benefits. Whether these findings are borne out over a wider population of HASS graduates calls for further research. Even as they stand, however, the results prompt several considerations for both universities and policy makers. Uppermost is the indication that enduring industry engagement, spanning pre, during and post-graduation, may confer additional value in the form of a highly industry engaged HASS academic labour force. Beneficiaries of this value-add are potentially non-university organisations, candidates and universities. Arguably, this important source of industry connectedness may be overlooked and under-utilised by universities and, with this, lost opportunities for building industry engagement from the connections these PhD candidates bring. This might include work integrated learning (WIL) opportunities for undergraduates, internship and mentoring opportunities for other research students, and opportunities for wider research collaborations.

In terms of the wider implications of these results, all three key findings have relevance for $\mathrm{PhD}$ employability debates. The common thread is a capacity to leverage non-university networks into, through and beyond the 
$\mathrm{PhD}$. In doing so, our cohort demonstrates a significant capacity for adaptability, including the ability to secure employment inside or outside the academy. The demonstrated adaptability and employability of HASS PhD graduates revealed in this study challenges some of the employability concerns prevalent in recent years, particularly 'doom and gloom' narratives about PhD graduates lacking transferable skills and being too highly specialised for employment beyond the academy (Cuthbert \& Molla, 2015). Our findings strongly suggest otherwise. Universities, for example, might refocus current efforts directed to industry engagement and employability initiatives for $\mathrm{PhD}$ students from their current settings which assume the PhD is a neophyte and all efforts to engage industry need to be university led. This might include more nuanced approaches which leverage off both the connections being brought to the university by candidates and their own employment and career trajectories.

\section{Conclusion}

The highly individual, as distinct from institutional, industry relationships which this research has revealed in HASS PhDs challenge the glib binary - as between university and industry - which is too readily applied in discussions of research industry and knowledge exchange. The investigation reported here contributes to a holistic understanding of the contemporary HASS PhD researcher as someone with a suite of skills, expertise and networks built up over time across multiple sectors. As we have showed, some $\mathrm{PhD}$ candidates in HASS are refashioning the $\mathrm{PhD}$ from the inside, deftly utilising the bespoke potential of the so-called 'traditional' $\mathrm{PhD}$ to advance numerous industry engagement and knowledge transfer objectives. The extensive pre-in- and postcandidature interactions with non-university sectors suggests the capacity for diverse pathways to impact in and from HASS PhDs, challenging the unidirectional, university-to-industry, model typical of normative accounts of knowledge transfer. By contrast, we reveal a model in which the PhD candidate functions as an industry engagement vector, bringing research problems and networks into the university from non-university organisations, with benefits potentially flowing both ways.

Our findings suggest numerous potential avenues for future research. We would welcome studies testing our results with a larger population of HASS graduates, or, alternatively, investigating whether these findings apply to other fields with a mature profile, such as business and management, or STEM-M. Our model of industry engagement extensiveness across the $\mathrm{PhD}$ research lifecycle might also be further tested and refined through such work. A further question raised by our research, which also calls for investigation, is how industry partners themselves value the engagement with $\mathrm{PhD}$ candidates and, where this leads to either university or nonuniversity employment, what sustained value-creation results. We look forward to further research on this important topic.

\section{References}

Ackers, L., Coey, C., Jons, H., Millard, D., Kupiszewski, M., Kupiszewska, D., et al. (2014). Mapping the population, careers, mobilities and impacts of advanced research degree graduates in the Social Sciences and Humanities. http://usir.salford.ac.uk/34678/1/POCARIM\%20D12\%20FINAL\%20REPORT.pdf. Accessed 27 February 2019.

Australian Research Council (2019). Engagement and impact assessment 2018-2019. https://dataportal.arc.gov.au/EI/NationalReport/2018/. Accessed June 122019.

Barnacle, R., Cuthbert, D., Schmidt, C., \& Batty, C. (2019). HASS PhD graduate careers and knowledge transfer: uncovering networks, 0, 1-22. Arts and Humanities in Higher Education. https://doi.org/10.1177/1474022219870976 Accessed November 92019.

Bell, J., Dodgson, M., Field, L., Gough, P., \& Spurling, T. (2015). Translating research for economic and social benefit: country comparisons. https://acola.org.au/wp/PDF/SAF09/SAF09\%20Full\%20report.pdf. Accessed 23 October 2018.

Bentley, P., Bexley, E., \& Dollinger, M. (2017). Mapping the external engagement of Australia’s PhD candidates. https://docs.wixstatic.com/ugd/f39714_e2519e18ec0e4f4ba8ec75c048b100d9.pdf. Accessed June 10 2018.

Brailsford, I. (2010). Motives and aspirations for doctoral study: career, personal, and inter-personal factors in the decision to embark on a history Ph.D. International Journal of Doctoral Studies, 5, 15-27. 
Cumming, J. (2007). Representing the complexity, diversity and particularity of doctoral enterprise in Australia. The Australian National University,

Cunningham, S., Theilacker, M., Gahan, P., Callan, V., \& Rainnie, A. (2016). Skills and capabilities for Australian enterprise innovation. http://acola.org.au/wp/PDF/SAF10/Full\%20report.pdf. Accessed 15 October 2017.

Cuthbert, D., \& Molla, T. (2015). The politicization of the PhD and the employability of doctoral graduates: an Australian case study in a global context. In D. E. Neubauer, \& K. Ghazali (Eds.), Technology and workplace skills for the twenty-first century: Asia Pacific universities in the globalized economy. New York; United Kingdom: Palgrave Macmillan.

Delamont, S., \& Atkinson, P. (2001). Doctoring uncertainty: mastering craft knowledge. Social Studies of Science, 31(1), 87-107, doi:10.1177/030631201031001005.

Duke Graduate School (2018). All departments: PhD completion rates. https://gradschool.duke.edu/about/statistics/all-departments-phd-completion-rates. Accessed 5 April 2018.

EPSRC (2014). New EPSRC Centres for doctoral training. https://www.epsrc.ac.uk/files/newsevents/news/cdtsinfographic/. Accessed 27 February 2018.

European Commission Horiozn 2020 (n.d.). Marie Skłodowska-Curie actions. https://ec.europa.eu/programmes/horizon2020/en/h2020-section/marie-sklodowska-curie-actions. Accessed 18 December 2019.

European Commission (n.d.). Innovative Training Networks. https://ec.europa.eu/info/fundingtenders/opportunities/portal/screen/opportunities/topic-details/msca-itn-2020. Accessed 18 December 2019.

Fochler, M., Felt, U., \& Müller, R. (2016). Unsustainable growth, hyper-competition, and worth in life science research: narrowing evaluative repertoires in doctoral and postdoctoral scientists' work and Lives. Minerva, 54, 175-200, doi175-200, doi:10.1007/s11024-016-9292-y.

Gardner, S. K. (2010). Contrasting the socialization experiences of doctoral students in high- and low completing departments: a qualitative analysis of disciplinary contexts at one institution. The Journal of Higher Education, 81(1), 61-81, doi:10.1080/00221546.2010.11778970.

Gibbons, M., Limoges, C., Nowotny, H., Schwartzman, S., Scott, P., \& Trow, M. (1994). The New Production of Knowledge: the Dynamics of Science and Research in Contemporary Societies. London: Sage.

Golde, C. M., \& Walker, G. E. (2006). Envisioning the future of doctoral education: preparing stewards of the discipline . San Francisco, CA.: Jossey-Bass; Carnegie Essays on the Doctorate.

Guerin, C. (2019). Stories of moving on HASS PhD graduates' motivations and career trajectories inside and beyond academia. Arts and Humanities in Higher Education, 1-21, doi:10.1177/1474022219834448.

Hasgall, A, Saenen, B, Borrell-Damian, L, Van Deynze, F, Seeber, M \& Huisman, J 2019, Doctoral education in Europe today: approaches and institutional structures. https://euacde.org/downloads/publications/online\%20eua\%20cde\%20survey\%2016.01.2019.pdf. Accessed 18 December 2019.

Hayden, M. C., Petrova, M. K., \& Wutti, D. (2018). Direct associations with the terminology of knowledge transfer: differences between the social sciences and humanities (SSH) and other scientific disciplines. TRAMES, 22 (72/67)(3), 239-256, doi:10.3176/tr.2018.3.02.

Higgins, S. C., \& Daniels, M. (2015). Alternative Academics: moving beyond the Academy. Journal of Eastern Mediterranean Archaeology \& Heritage Studies, 3(3), 238-246.

Holbrook, A., Shaw, K., Scevak, J., Bourke, S., Cantwell, R., \& Budd, J. (2014). PhD candidate expectations: exploring mismatch with experience. International Journal of Doctoral Studies, 9, 329-346, doi:10.28945/2078. 
Howard, J. H. (2015). Translation of research for economic and social benefit: measures that facilitate transfer of knowledge from publicly funded research organisations to industry.

https://www.howardpartners.com.au/assets/john-howard---translation-of-research-for-economic-and-socialbenefit---10-nov-2015.pdf. Accessed 24 October 2018.

Hughes, A., Kitson, M., Probert, J., Bullock, A., \& Milner, I. (2011). Hidden connections: knowledge exchange between the arts and humanities and the private, public and third sectors.

https://www.cbr.cam.ac.uk/fileadmin/user_upload/centre-for-business-research/downloads/specialreports/specialreport-hiddenconnections.pdf. Accessed 7 February 2019.

Hughes, A., Kitson, M., Probert, J., Turner, R., Bullock, A., \& Milner, I. (2014). Cultural connections: the role of the arts and humanities in competitveness and local development.

https://www.jbs.cam.ac.uk/fileadmin/user_upload/centre-for-business-research/downloads/specialreports/specialreport-culturalconnections.pdf. Accessed 7 July 2019.

Hughes, A., Lawson, C., Salter, A., Bullock, A., \& Hughes, R. B. (2016). The changing state of knowledge exchange: UK academic interactions with external organisations 2005 -2015.

http://www.ncub.co.uk/index.php?option=com_docman\&view=download\&category_slug=reports\&alias=429the-changing-state-of-knowledge-exchange\&Itemid=2728. Accessed 11 April 2019.

Innovate UK (2018). Knowledge Transfer Partnerships. http://ktp.innovateuk.org/. Accessed 25 October 2018.

Jonker, L. (2016). Ontario’s PhD graduates from 2009: where are they now?

http://www.heqco.ca/SiteCollectionDocuments/Ontario\%27s-PhD-Graduates-from-2009-ENG.pdf. Accessed 3 February 2018.

Kjellberg, H., Mallard, A., Arjalies, D.-L., Aspers, P., Beljean, S., Bidet, A., et al. (2013). Valuation studies? Our collective two cents. Valuation Studies, 1(1), 11-30, doi:10.3384/vs.2001-5992.131111.

Klein, H. K., \& Rowe, F. (2008). Marshaling the professional experience of doctoral students: a contribution to the practical relevance debate. MIS Quarterly, 32(4), 675-686, doi:10.2307/25148866.

Lamont, M. (2012). Toward a comparative sociology of valuation and evaluation. Annual Review of Sociology, 38(1), 201-221, doi:10.1146/annurev-soc-070308-120022.

Litalien, D., Guay, F., \& Morin, A. J. S. (2015). Motivation for Ph.D. studies: scale development and validation. Learning and Individual Differences, 41, 1-13, doi:10.1016/j.lindif.2015.05.006.

Markuerkiaga, L., Errasti, N., \& Igartua, J. I. (2014). Success factors for managing an entrepreneurial university. Industry \& Higher Education, August, 233-244, doi:10.5367/ihe.2014.0214.

McAlpine, L., \& Amundsen, C. (2016). Post-PhD career trajectories: intentions, decision-making and life aspirations. Palgrave Macmillan.

McAlpine, L., \& Austin, N. (2018). Humanities PhD graduates: desperately seeking careers? Canadian Journal of Higher Education, 48(2), 1-19.

McCarthy, M. T. (2017). Promising practices in humanities PhD professional development.

http://cgsnet.org/publication-pdf/5049/NEH_NextGen_LessonsLearned.pdf. Accessed June 292018.

Mewburn, I., Grant, W. J., Suominen, H., \& Kizimchuk, S. (2018). A machine learning analysis of the nonacademic employment opportunities for Ph.D graduates in Australia. Higher Education Policy, doi:10.1057/s41307-018-0098-4.

Molla T. M., \& Cuthbert, D. (2018). Re-imagining Africa as a knowledge economy: premises and promises of recent higher education development initiatives. Journal of Asian and African Studies, 53, 250-267, doi:10.1177/0021909616677370. 
Moxham, L., Dwyer, T. A., \& Reid-Searl, K. (2013). Articulating expectations for PhD candidature upon commencement: ensuring supervisor/student "best fit". Journal of Higher Education Policy and Management, 35(4), 345-354.

Norton, A., Cherastidtham, I., \& Mackey, W. (2018). Mapping Australian higher education 2018. http://www.5050foundation.edu.au/assets/reports/documents/907-Mapping-Australian-higher-education2018.pdf. Accessed 23 January 2019.

OECD.Stat (2019). Distribution of graduates and entrants by Field. https://stats.oecd.org/Index.aspx? Accessed 26 February 2019.

Olmos-Peñuela, J., Castro-Martínez, E., \& D’Este, P. (2014). Knowledge transfer activities in social sciences and humanities: explaining the interactions of research groups with non-academic agents. Research Policy, 43, 696-706, doi:10.1016/j.respol.2013.12.004.

Pearson, M., Cumming, J., Evans, T., Macauley, P., \& Ryland, K. (2011). How shall we know them? capturing the diversity of difference in Australian doctoral candidates and their experiences. Studies in Higher Education, 36(5), 527-542, doi:10.1080/03075079.2011.594591.

Raddon, A., \& Sung, J. (2009). The career choices and impact of PhD graduates in the UK: a synthesis review. https://esrc.ukri.org/files/public-engagement/public-dialogues/full-report-phd-graduates-career-choices/.

Accessed 16 January 2019.

Robertson, M., J (2017). Ages and career stages: considerations in providing support for mid-late career stage doctoral students. Innovations in Education and Teaching International, 54(6), 560-569, doi:10.1080/14703297.2017.1355261.

School of Graduate Studies University of Toronto (2018). Employed and Engaged: Career Outcomes of Our PhD Graduates, 2000-2015. http://www.sgs.utoronto.ca/about/Pages/10,000-PhDs-Project.aspx. Accessed 12 June 2018.

Skakni, I. (2018). Reasons, motives and motivations for completing a PhD: a typology of doctoral studies as a quest. Studies in Graduate and Postdoctoral Education, 9(2), 197-212, doi:10.1108/SGPE-D-18-00004.

Stanford Institutional Research \& Decision Support (2018). Stanford PhD alumni employment project. http://web.stanford.edu/dept/pres-provost/irds/phdjobs. Accessed 4 January 2018.

Stokes, D. E. (1997). Pasteur's quadrant: basic science and technological innovation. Washington, DC: Brookings Institution Press.

Thune, T. (2009) Doctoral students on the university-industry interface: a review of the literature. Higher Education, 58, 637-651 doi:10.1007/s10734-009-9214-0

UBC Faculty of Graduate \& Postdoctoral Studies (2017). UBC PhD Career Outcomes (February 26 2018),

Universities Australia (2016). Clever collaborations: the strong business case for partnering with universities. https://www.universitiesaustralia.edu.au/Media-and-Events/submissions-and-reports/Clever-Collaborations. Accessed 15 January 2019.

University of Cambridge Enterprise (2015). UK University Technology Transfer: Behind the headlines. https://www.enterprise.cam.ac.uk/wp-content/uploads/2015/04/Behind-the-headlines.pdf. Accessed 7 February 2019.

University of Copenhagen (2019). The industrial PhD program. https://healthsciences.ku.dk/phd/apply/routesto-a-phd/industrialphd/. Accessed 18 December 2019. 